\title{
Visible light photocatalytic properties of novel molybdenum treated carbon nanotube/titania composites
}

\author{
FENG-JUN ZHANG ${ }^{\dagger}$ and WON-CHUN OH* \\ School of Materials and Chemical Engineering, Anhui University of Architecture, Anhui Hefei 230022, \\ P. R. China \\ ${ }^{\dagger}$ Department of Advanced Materials \& Engineering, Hanseo University, Seosan-si, Chungnam-do 356-706, Korea
}

MS received 17 August 2010; revised 21 October 2010

\begin{abstract}
Two types of molybdenum-carbon nanotubes and molybdenum treated carbon nanotubes/titania composites were prepared using a sol-gel method. These composites were characterized comprehensively by the BrauerEmett-Teller (BET) surface area, scanning electron microscopy (SEM), energy dispersive X-ray (EDX) analysis, X-ray diffraction (XRD), transmission electron microscopy (TEM) and UV-vis absorption spectroscopy. It was found that the photocatalytic degradation of a methylene blue solution could be attributed to the combined effects caused by the photo-degradation of titania, the electron assistance of carbon nanotube network, and the enhancement of molybdenum. The proposed redox mechanism of the photodegradation of methylene blue on Mo-CNT/TiO composites is suggested.
\end{abstract}

Keywords. Molybdenum; carbon nanotube; titania; photocatalytic; visible light.

\section{Introduction}

$\mathrm{TiO}_{2}$ has attracted considerable interest as a photo catalyst for various degradation reactions of organic contaminants due to its stability, inexpensive and low biological toxicity (Bessekhouad et al 2003; Jung et al 2004; Kozlova et al 2004). However, the wide technological use of $\mathrm{TiO}_{2}$ is impaired by its large bandgap $(3.2 \mathrm{eV})$, which requires UV irradiation. Therefore, for practical applications, attempts have been made to support $\mathrm{TiO}_{2}$ nanoparticles on porous adsorbent materials and to extend the light absorption of the photocatalysts to the visible region (Yoneyama and Torimoto 2000; Bhattacharyya et al 2004; Carp et al 2004; Hamal and Klabunde 2007; Neren Ökte and Özge 2008). Moreover, several researchers have already attempted to reduce the bandgap energy of $\mathrm{TiO}_{2}$ through doping with transition metal ions (Di Paola et al 2002; Devi et al 2009).

Recently, carbon supported catalysts have attracted increasing attention (Farag et al 1999; Li et al 2001; Fu et al 2004; Oh et al 2007; Yang et al 2007; Oh and Chen 2008; Zhang et al 2008, 2009). Carbon nanotubes (CNTs) are a type of novel carbon material with unique mechanical and electronic properties (Dai et al 1996; Zhang et al 1999), which can be regarded as hollow graphite fibre with a perfect structure, such as seamless tube-like graphitic walls consisting of $s p^{2}$ carbon-carbon atoms, nano-sized hollow channels, excellent electron-transporting capability as well

\footnotetext{
*Author for correspondence (wc_oh@hanseo.ac.kr; zhang-fengjun@hotmail.com)
}

as convertible surface properties that can be modified easily. Overall, these properties make CNTs good candidates as catalyst supports.

Doping is also a promising approach for reducing the absorption threshold of $\mathrm{TiO}_{2}$ and extending its optical absorption range from the ultraviolet to visible region (Asahi et al 2001). Therefore, a large number of studies focusing on doping of $\mathrm{TiO}_{2}$ with metal or nonmetal elements have been reported over the past decade and demonstrated obvious visible-light activity (Thompson and Yates 2006; Chen and Mao 2007). Choi et al (1994) examined $\mathrm{TiO}_{2}$ doped with 21 different transition metal ions and reported a significant increase in the photo-reactivity of $\mathrm{TiO}_{2}$ samples for both chloroform oxidation and reduction when $\mathrm{Fe}^{3+}, \mathrm{Mo}^{5+}$, $\mathrm{Ru}^{3+}, \mathrm{Os}^{3+}, \mathrm{Re}^{5+}, \mathrm{V}^{4+}$ and $\mathrm{Rh}^{3+}$ were used at $0 \cdot 1-0 \cdot 5 \%$. Molybdenum appears to be one of these potentially interesting additives because it is inexpensive and largely available. However, the partially occupied impurity bands can act as recombination centres where photoinduced charge carriers recombine, resulting in a decrease in charge carrier quantity and photocatalytic activity in some single-doped $\mathrm{TiO}_{2}$.

Although Mo-doped $\mathrm{TiO}_{2}$ and CNT-supported $\mathrm{TiO}_{2}$ were reported to exhibit enhanced vis-photocatalytic activity compared with pure $\mathrm{TiO}_{2}$ (Choi et al 1994; Oh and Chen 2008; Devi et al 2009), there are a few reports on Mo-treated CNT as supported materials for $\mathrm{TiO}_{2}$ photocatalyst. In this study, Mo-CNT/ $/ \mathrm{TiO}_{2}$ composites were synthesized using a solgel method. The mechanisms of enhanced visible-light activity and photocatalytic performance in $\mathrm{Mo}-\mathrm{CNT} / \mathrm{TiO}_{2}$ are discussed. 


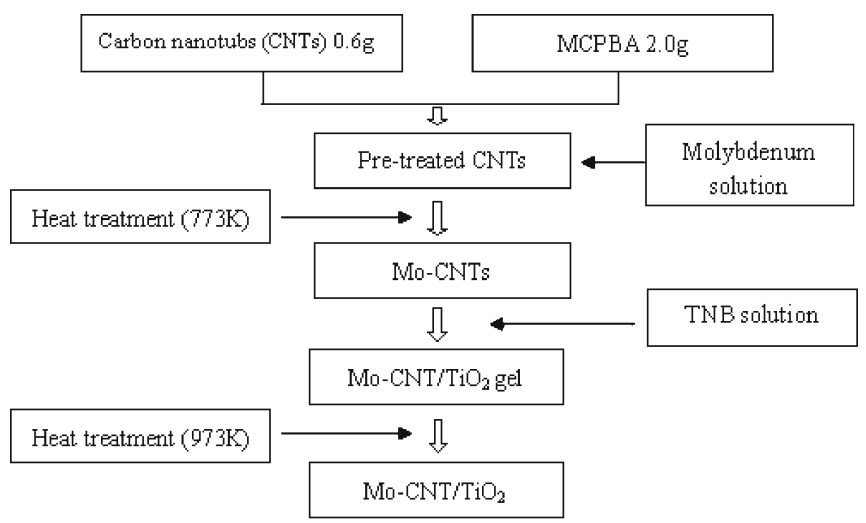

Figure 1. Flow chart of fabrication of $\mathrm{Mo}-\mathrm{CNT} / \mathrm{TiO}_{2}$ composites

\section{Experimental}

\subsection{Materials}

Carbon nanotubes (CNTs) were selected as the support material. The CNTs (multiwall nanotubes, diameter: $\sim 20 \mathrm{~nm}$, length: $\sim 5 \mu \mathrm{m}$ ) were supplied by Carbon Nano-Material Technology Co., Ltd, Korea and used as received. TNB (Ti $\left.\left(\mathrm{OC}_{4} \mathrm{H}_{7}\right)_{4}\right)$ as a titanium source for the preparation of the composites was purchased from Acros Organics, New Jersey, USA. $m$-chloroperbenzoic acid (MCPBA, Acros Organics, New Jersey, USA) was used as an oxidized reagent for oxidization of CNT surface. Analytical grade methylene blue was purchased from Duksan Pure Chemical Co., Ltd, Korea. Ammonium molybdate was obtained from Samchun Pure Chemical Co., Ltd, Korea. The reagent-grade solvents, benzene and ethyl alcohol, were acquired from Duksan Pure Chemical Co. and Daejung Chemical Co., Korea and used as received.

\subsection{Preparation of Mo-CNT composites}

MCPBA (2.0 g) as an oxidizing agent was dissolved in $60 \mathrm{~mL}$ benzene. CNTs $(0.6 \mathrm{~g})$ were added to the oxidizing agent, heated under reflux for $6 \mathrm{~h}$, filtered and dried. The oxidized CNTs were added to a solution containing ammonium molybdate at various concentrations, and the solutions were

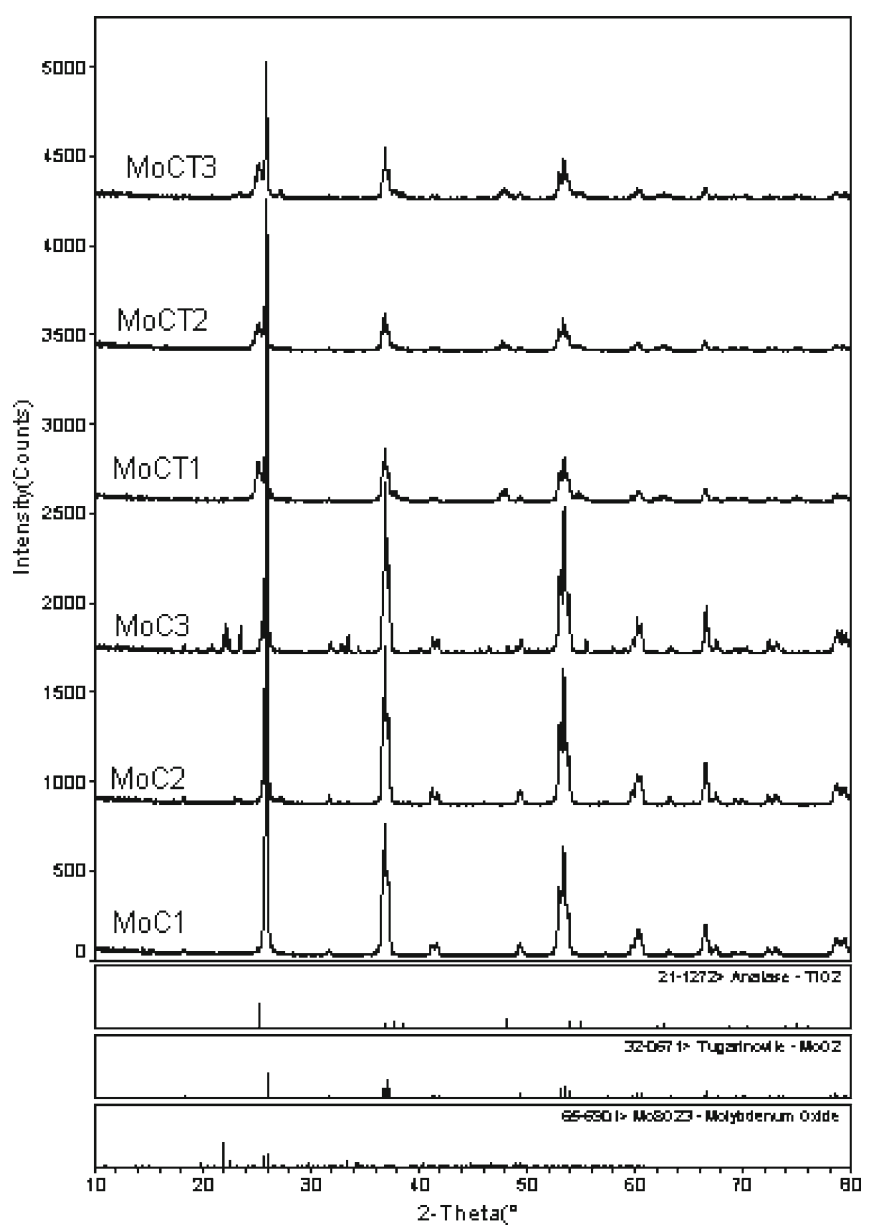

Figure 2. XRD patterns of $\mathrm{Mo}-\mathrm{CNT} / \mathrm{TiO}_{2}$ composites.

then homogenized under reflux at $343 \mathrm{~K}$ for $5 \mathrm{~h}$ using a magnetic stirrer. After heat treatment at $773 \mathrm{~K}$ for $1 \mathrm{~h}$, the Mo treated CNT composites were obtained.

\subsection{Preparation of $\mathrm{Mo}-\mathrm{CNT} / \mathrm{TiO}_{2}$ composites}

The Mo treated CNT composites were placed into the TNB and benzene at a volume ratio of $4: 16$. The solutions were then homogenized under reflux at $343 \mathrm{~K}$ for $5 \mathrm{~h}$. After stirring, the solutions transformed to $\mathrm{Mo}-\mathrm{CNT} / \mathrm{TiO}_{2}$ gels. The gels were heated at $973 \mathrm{~K}$ for $1 \mathrm{~h}$. After cooling, the Mo$\mathrm{CNT} / \mathrm{TiO}_{2}$ composites were produced. Figure 1 and table 1

Table 1. Nomenclatures and surface areas of $\mathrm{Mo}-\mathrm{CNT} / \mathrm{TiO}_{2}$ composites.

\begin{tabular}{lcc}
\hline Preparation method & Nomenclatures & $S_{\mathrm{BET}}\left(\mathrm{m}^{2} / \mathrm{g}\right)$ \\
\hline $0.6 \mathrm{~g} \mathrm{CNT}+$ ammonium molybdate $(0 \cdot 01 \mathrm{M})$ & MoC1 & 181 \\
0.6 g CNT+ ammonium molybdate $(0.02 \mathrm{M})$ & MoC2 & 172 \\
$0.6 \mathrm{~g} \mathrm{CNT}+$ ammonium molybdate $(0.03 \mathrm{M})$ & MoC3 & 165 \\
0.6 g CNT+ ammonium molybdate $(0 \cdot 01 \mathrm{M})+\mathrm{TNB} 4 \mathrm{~mL}$ & MoCT1 & 106 \\
0.6 g CNT+ ammonium molybdate $(0 \cdot 02 \mathrm{M})+\mathrm{TNB} 4 \mathrm{~mL}$ & MoCT2 & 101 \\
$0.6 \mathrm{~g} \mathrm{CNT}+$ ammonium molybdate $(0.03 \mathrm{M})+\mathrm{TNB} 4 \mathrm{~mL}$ & MoCT3 & 94 \\
\hline
\end{tabular}


show the preparation conditions and nomenclatures of the samples.

\subsection{Characterization of the $\mathrm{Mo}-\mathrm{CNT} / \mathrm{TiO}_{2}$ composites}

X-ray diffraction (XRD) was used for crystal phase identification and to estimate the anatase-to-rutile ratio. The XRD patterns were obtained at room temperature with a Shimata XD-D1 (Japan) diffractometer using $\mathrm{Cu} \mathrm{K} \alpha$ radiation. Scanning electron microscopy (SEM, JEOL, JSM-5200, Japan) was used to observe the surface state and porous structure of the Mo- $\mathrm{CNT} / \mathrm{TiO}_{2}$ composites. Energy dispersive $\mathrm{X}$-ray (EDX) spectroscopy was used to measure the elemental analysis of Mo-CNT/TiO 2 composites. Transmission electron microscopy (TEM, JEOL, JEM-2010, Japan) at an acceleration voltage of $200 \mathrm{kV}$ was used to examine the size and distribution of molybdenum and titanium deposits on CNT surface. The TEM specimens were prepared by placing a drop of a sample solution onto a carbon grid.

\subsection{Photocatalytic $(P C)$ decolourization of $M B$}

PC decolourization was performed using $\mathrm{Mo}-\mathrm{CNT} / \mathrm{TiO}_{2}$ composites in a $100 \mathrm{~mL}$ glass container and the system was then irradiated with visible light (8W, KLD-08L/P/N, Fawoo Technology) placed $100 \mathrm{~mm}$ from the solution in dark box. Prior to illumination, the composites were impregnated in the pristine MB solution in the dark for 120 minutes to achieve adsorption/desorption equilibrium. The $\mathrm{Mo}-\mathrm{CNT} / \mathrm{TiO}_{2} \mathrm{com}-$ posites were placed in $50 \mathrm{~mL}$ of $1.0 \times 10^{-5} \mathrm{~mol} / \mathrm{L} \mathrm{MB}$ solution. The PC degradation of $\mathrm{MB}$ was performed using visible light. The $\mathrm{PC}$ activity of $\mathrm{Mo}-\mathrm{CNT} / \mathrm{TiO}_{2}$ composites
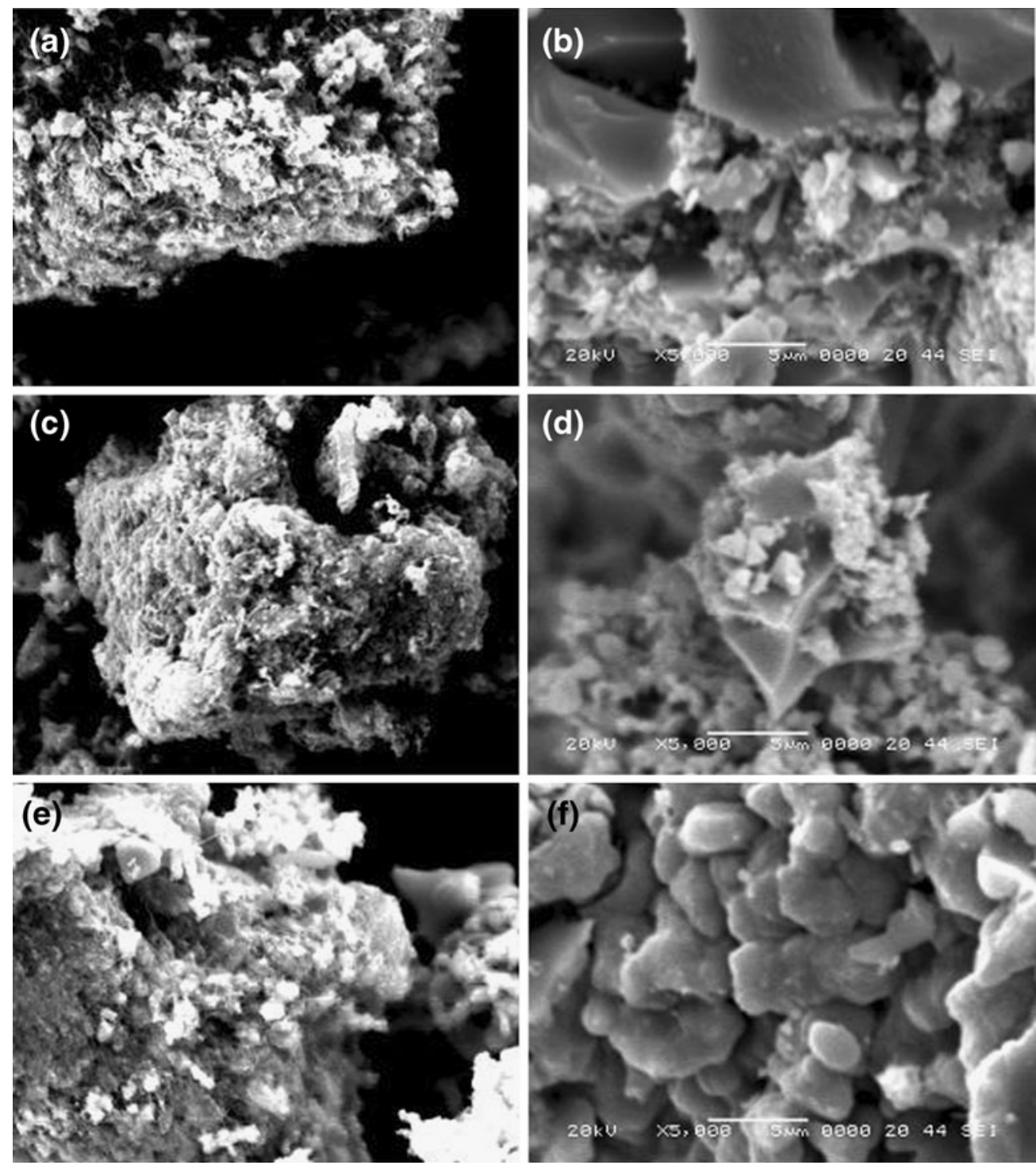

Figure 3. SEM images obtained from powdered Mo-CNT and $\mathrm{Mo}-\mathrm{CNT} / \mathrm{TiO}_{2}$ composites. (a) $\mathrm{MoC} 1$, (b) MoCT1, (c) MoC2, (d) MoCT2, (e) MoC3 and (f) MoCT3. 
was investigated using the rate $\mathrm{PC}$ decolourization of the $\mathrm{MB}$ solution, which was measured as a function of time. The MB concentration in the solution was determined from the change in absorbance at $660 \mathrm{~nm}$ as a function of irradiation time.

\section{Results and discussion}

\subsection{Structure and morphology of $\mathrm{Mo}-\mathrm{CNT/} \mathrm{TiO}_{2}$ composites}

Table 1 lists the BET surface areas of Mo-CNT and Mo-CNT/TiO 2 composites. The BET surface areas of the molybdenum-treated $\mathrm{CNT} / \mathrm{TiO}_{2}$ composites decreased gradually from 106 to $94 \mathrm{~m}^{2} / \mathrm{g}$ with increasing molybdenum concentration but the BET surface areas of non-molybdenum treated $\mathrm{CNT} / \mathrm{TiO}_{2}$ composites also decreased from 181$165 \mathrm{~m}^{2} / \mathrm{g}$. This shows that the BET surface area of the $\mathrm{CNT} / \mathrm{TiO}_{2}$ composite decreases after the formation of $\mathrm{TiO}_{2}$ particles by TNB treatment. At the same addition of TNB, the
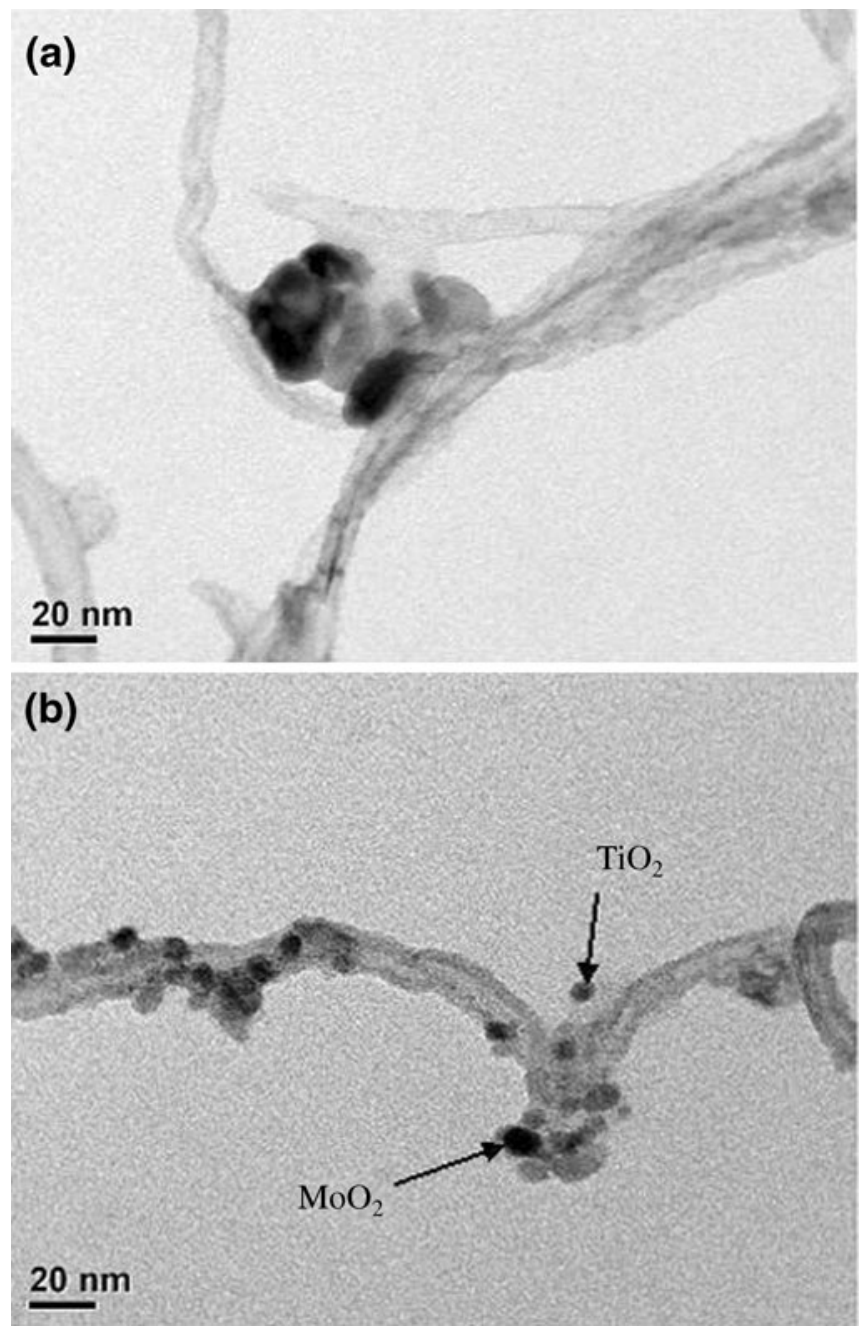

Figure 4. TEM micrographs obtained from powdered Mo-CNT and $\mathrm{Mo}-\mathrm{CNT} / \mathrm{TiO}_{2}$ composites. (a) MoC3 and (b) MoCT3. intensity of Mo particle aggregation increased with increasing molybdenum concentration. These particles were heavily agglomerated to gather into blocky-shaped particles. These results can be seen clearly from the SEM images obtained from powdered $\mathrm{Mo}-\mathrm{CNT} / \mathrm{TiO}_{2}$ composites. The BET surface area of the $\mathrm{Mo}-\mathrm{CNT} / \mathrm{TiO}_{2}$ composites decreased after the formation of Mo particles by molybdenum treatment. This suggests that some porosity had developed during heat treatment. The composites are believed to be nano materials with many micropores, which were blocked partially by the formation of Mo particles on the $\mathrm{CNT} / \mathrm{TiO}_{2}$ surface during heat treatment. As expected, the BET surface area decreases due to the blocking of these micropores by surface complexes introduced through the formation of $\mathrm{Mo}-\mathrm{CNT} / \mathrm{TiO}_{2}$ composites.

Figure 2 presents XRD results for the catalyst samples. The structure of the molybdenum treated $\mathrm{CNT} / \mathrm{TiO}_{2}$ composites showed an anatase crystal. The crystal structure of titanium dioxide is determined mainly by heat treated temperature. The peaks at $25.3,37.8,48.0$ and $62.5^{\circ} 2 \theta$ were assigned to the (101), (004), (200) and (204) diffraction planes of anatase, indicating that the developed $\mathrm{CNT} / \mathrm{TiO}_{2}$ composites have an anatase structure when annealed at $973 \mathrm{~K}$.

The XRD patterns of Mo-CNT and Mo-CNT/TiO 2 samples showed (111), (211), (312), (210), (310) and (031) diffraction peaks for the monoclinic $\mathrm{MoO}_{2}$ phase, which formed during the calcination process. Intense anatase peaks still appeared in the Mo-CNT/ $/ \mathrm{TiO}_{2}$ samples. Although it is unclear in figure 2, only the $\mathrm{MoC} 3$ sample showed $\mathrm{MoO}_{2}$ and $\mathrm{Mo}_{8} \mathrm{O}_{23}$. Unfortunately, these high angle diffraction peaks are complicated and not easily detected in the figure because of the overlapping diffraction peaks attributed to $\mathrm{TiO}_{2}$, molybdenum oxides and those of the CNTs support.

The micro-surface structures and morphology of the Mo$\mathrm{CNT} / \mathrm{TiO}_{2}$ composites were characterized by SEM (figure 3 ). Figure 3 shows the macroscopic changes in the morphology of the $\mathrm{Mo}-\mathrm{CNT} / \mathrm{TiO}_{2}$ composites. As shown in figure 3 , the $\mathrm{TiO}_{2}$ particles were well attached to the surface of the CNT network and the distribution was uniform. Zhang et al (2005) reported that a good dispersion of small particles can provide more reactive sites for the reactants than

Table 2. EDX elemental microanalysis of $\mathrm{Mo}-\mathrm{CNT} / \mathrm{TiO}_{2}$ composites.

\begin{tabular}{llccc}
\hline Samples & \multicolumn{2}{l}{ Element (wt. \%) } & & \\
\cline { 2 - 5 } & $\mathrm{C}$ & $\mathrm{O}$ & $\mathrm{Ti}$ & Mo \\
\hline MoC1 & $34 \cdot 2$ & $22 \cdot 3$ & 0 & $39 \cdot 5$ \\
MoC2 & $31 \cdot 9$ & $20 \cdot 6$ & 0 & $47 \cdot 5$ \\
MoC3 & $29 \cdot 4$ & $17 \cdot 6$ & 0 & $53 \cdot 0$ \\
MoCT1 & $22 \cdot 1$ & $40 \cdot 4$ & $15 \cdot 1$ & $22 \cdot 3$ \\
MoCT2 & $23 \cdot 2$ & $38 \cdot 8$ & $14 \cdot 5$ & $23 \cdot 5$ \\
MoCT3 & $22 \cdot 2$ & $35 \cdot 2$ & $13 \cdot 2$ & $28 \cdot 4$ \\
\hline
\end{tabular}


aggregated particles. At the same time, the conductivity of CNT network can facilitate electron transfer between the adsorbed dye molecules and catalyst substrate (Christensen et al 2003), which is beneficial for the enhancement of PC activity of these composites.

Moreover, molybdenum oxide particles were fixed to the surface of the CNT network in small clusters, and the distribution was not uniform. Moreover, for the Mo-CNT samples (figures 3(a), (c), (e)), there was no clear difference in the intensity of aggregation molybdenum oxide particles, but for the $\mathrm{Mo}-\mathrm{CNT} / \mathrm{TiO}_{2}$ composites, these particles were heavily agglomerated to form blocky-shaped particles (figures 3(b), (d), (f)), which were more uniform in the MoCT3 sample. These results were confirmed by TEM observations of the Mo-CNT and Mo-CNT/TiO 2 composites. As shown in figure 4, for the Mo-CNT composites, the Mo oxide particles were aggregated on the outer surface of the CNT tubes (figure 4(a)), whereas for the $\mathrm{Mo}-\mathrm{CNT} / \mathrm{TiO}_{2}$ composites, the Mo oxide particles attached to the surface of the tubes also caused partial agglomeration to form blocky-shaped particles (figure 4(b)). Moreover, the particle sizes of Mo oxide decrease due to the formation of $\mathrm{TiO}_{2}$ on the surface of the tubes.

Table 2 lists the results of EDX elemental microanalysis of the Mo-CNT/ $\mathrm{TiO}_{2}$ composites. The content of molybdenum in MoCT1, MoCT2, and MoCT3 was 22.3, 23.5, and $28.4 \%$, respectively. The molybdenum content in the composites increased with increasing molybdenum concentration in the initial solution.

\subsection{PC decolorization of $M B$}

Figure 5 shows the dark adsorption efficiency of the MoC and MoCT composites for MB degradation. After adsorption in the dark for $2 \mathrm{~h}$, all the samples reached adsorption-

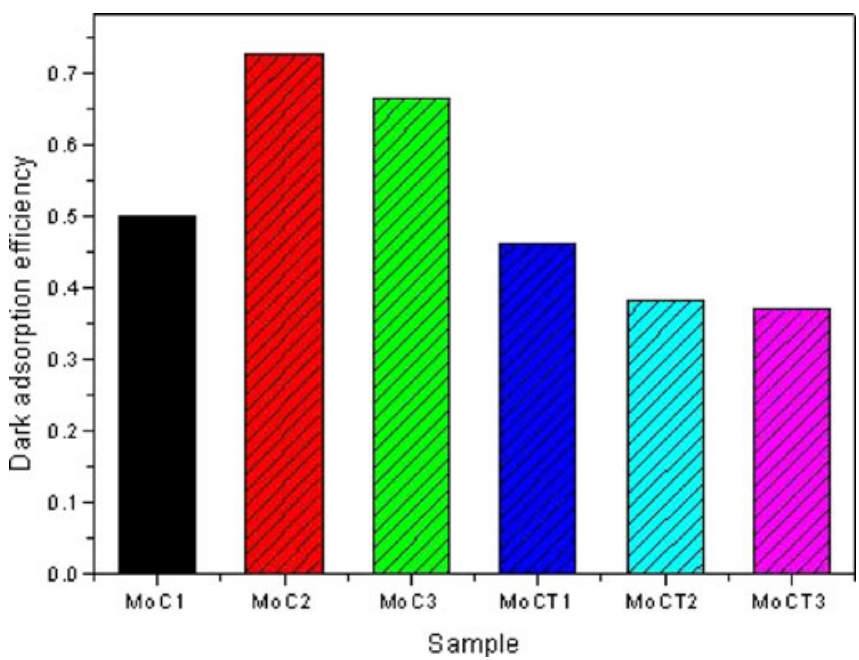

Figure 5. Dark adsorption efficiency of MoC and MoCT composites for MB degradation.

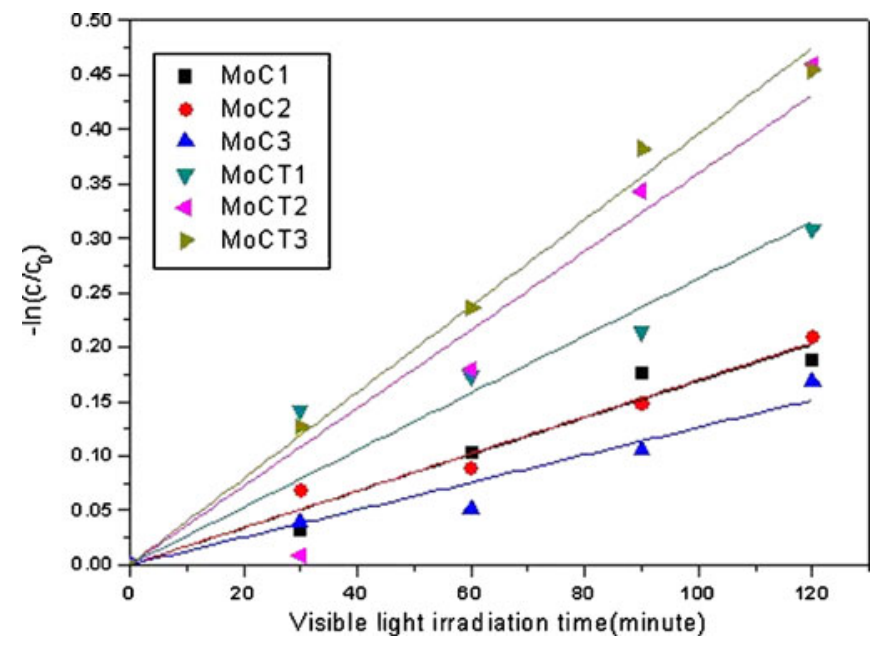

Figure 6. Apparent first-order linear transform $-\ln \left(\mathrm{c} / \mathrm{c}_{0}\right)$ against irradiation time of $\mathrm{MB}$ degradation kinetic plots for $\mathrm{Mo}-\mathrm{C}$ and $\mathrm{Mo}-$ CT composites.

desorption equilibrium. The concentration of $\mathrm{MB}$ in solution was decreased by only 49.9-72.6\% using MoC samples. However, the MoCT samples decreased the concentrations of the MB solution by $36 \cdot 9-46 \cdot 0 \%$. For the MoCT samples, the BET surface areas decreased with increasing molybdenum concentration. The results of adsorption are consistent with the BET surface areas.

Figure 6 shows PC degradation rate of MB for different $\mathrm{MoC}$ and MoCT composites under visible light irradiation. The PC effects of the Mo- $\mathrm{CNT} / \mathrm{TiO}_{2}$ composites were superior to that of Mo-CNT at an irradiation time of $120 \mathrm{~min}$. Moreover, for the Mo treated $\mathrm{CNT} / \mathrm{TiO}_{2}$ series, the PC degradation efficiency of the sample MoCT3 was higher than that of the other samples at an irradiation time of $120 \mathrm{~min}$. The catalytic activity of Mo particles for this reaction is dependent on a range of factors, which involves the size and dispersion of the particles, supporting materials and their surface conditions. In the case of MoCT1 and MoCT2, the Mo particles were heavily agglomerated to gather into blocky-shaped particles (figures 3(b) and (f)), which leads to a significant decrease in activity. The PC activity increased with increasing Mo content over a certain range. At the same time, the

Table 3. Kinetic constants of MB degradation.

\begin{tabular}{lcc}
\hline Photocatalyst & $\begin{array}{c}\text { Kinetic constants } \\
\left(\mathrm{k}, \mathrm{min}^{-1}\right)\end{array}$ & $\begin{array}{c}\text { Correlation } \\
\text { coefficient }\left(R^{2}\right)\end{array}$ \\
\hline MoC1 & 0.00169 & 0.9818 \\
MoC2 & 0.0017 & 0.9914 \\
MoC3 & 0.00126 & 0.9737 \\
MoCT1 & 0.00263 & 0.9685 \\
MoCT2 3 & 0.00359 & 0.9571 \\
\hline
\end{tabular}




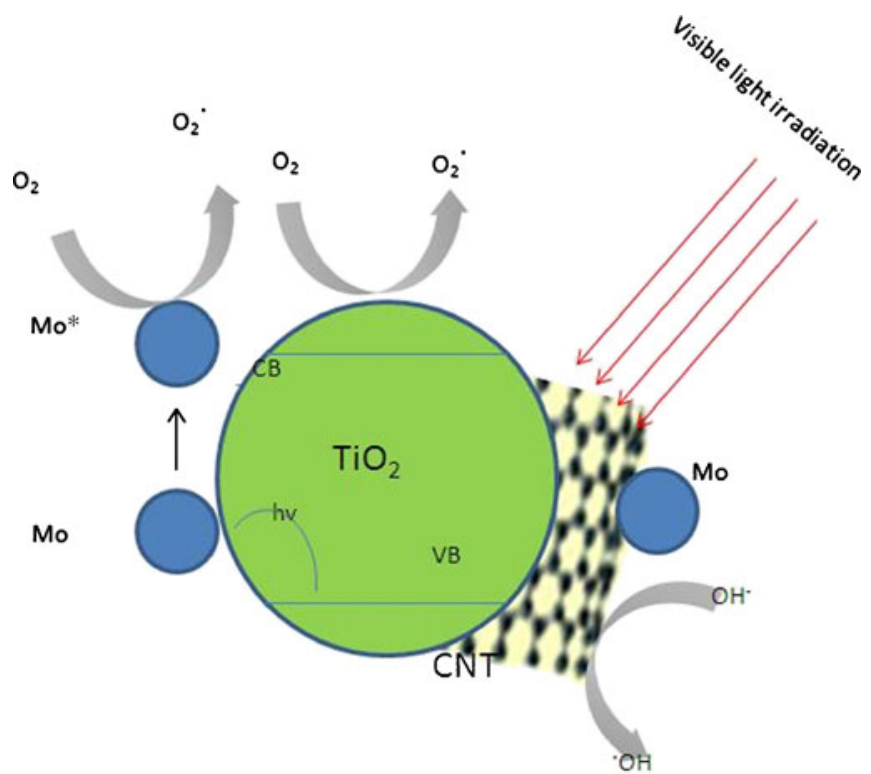

Figure 7. Proposed redox mechanism of $\mathrm{Mo}-\mathrm{CNT} / \mathrm{TiO}_{2}$ composites under visible-light irradiation.

morphology of Mo in the $\mathrm{Mo}-\mathrm{CNT} / \mathrm{TiO}_{2}$ composites is an important factor.

\subsection{Proposed redox mechanism of $\mathrm{Mo}-\mathrm{CNT/TiO}$}

Table 3 lists the observed kinetic constants. The first-order kinetics constant increased with increasing Mo addition in the Mo-CNT and Mo- $\mathrm{CNT} / \mathrm{TiO}_{2}$ composites, suggesting that the addition of Mo enhanced the photoactivity. Based on the relevant band positions of $\mathrm{Mo}$ and $\mathrm{TiO}_{2}$, the Mo clusters at lower concentrations acted as a separation centre. The photogenerated electrons were transferred from the $\mathrm{TiO}_{2}$ conduction band to the Mo conduction band, and holes accumulated in the $\mathrm{TiO}_{2}$ valence band. Therefore, the photogenerated electrons and holes were separated efficiently. The observed kinetics constants of Mo-CNT were $0.00169 \mathrm{~min}^{-1}\left(R^{2}=0.9818\right), 0.0017 \mathrm{~min}^{-1}\left(R^{2}=\right.$ $0.9914)$ and $0.00126 \mathrm{~min}^{-1}\left(R^{2}=0.9737\right)$, respectively; and $\mathrm{Mo}-\mathrm{CNT} / \mathrm{TiO}_{2}$ were $0.00263 \mathrm{~min}^{-1}\left(R^{2}=0.9685\right)$, $0.00359 \mathrm{~min}^{-1}\left(R^{2}=0.9571\right)$ and $0.00396 \mathrm{~min}^{-1}\left(R^{2}=\right.$ $0.9965)$, respectively. Therefore, the first-order kinetics constant of Mo-CNT/TiO 2 was $\sim 1 \cdot 5-3 \cdot 1$ times higher than that of Mo-CNT at the same addition of Mo solution. In the case of $\mathrm{Mo}-\mathrm{CNT} / \mathrm{TiO}_{2}$, the $\mathrm{PC}$ reactions were quite versatile because of the multicomponent nature, and the chemical substances destroyed or transformed photocatalytically is almost unlimited.

MoCT1, MoCT2 and MoCT3 have a good PC activity under visible light irradiation. Figure 7 shows the proposed redox mechanism of $\mathrm{Mo}-\mathrm{CNT} / \mathrm{TiO}_{2}$ composites under visible-light irradiation. These electrons tend to reduce the Ti (IV) cations to a Ti (III) state; the holes oxidize $\mathrm{O}_{2}^{-}$anions.
In this process oxygen atoms are ejected, creating oxygen vacancies. Water molecules can then occupy these oxygen vacancies, producing adsorbed $\mathrm{OH}$ groups, which tend to produce HO. The PC activity is enhanced because more $\mathrm{OH}$ groups can be adsorbed on the surface. On the other hand, the surface of these composites can adsorb contaminated compounds, which tends to convert the hydrophilic surface to a hydrophobic one. Photocatalysis can decompose the organic pollutants on the surface. The realization of a charge-separated electron transfer with photo-responsive function will lead to an achievement of novel photocatalysts. Such electron transfer has been achieved by semiconductors (Matsui et al 2009a, b) and may be achieved by a combination of CNTs and nano-sized semiconductors, in which the carbon parts are expected to act as visible light absorption sites and an electron transfer bed, and semiconductors to act as an electron excitation sites, resulting in visible light absorption and electron excitation.

\section{Conclusions}

This paper reports the synthesis and characterization of Mo$\mathrm{CNT}$ and $\mathrm{Mo}-\mathrm{CNT} / \mathrm{TiO}_{2}$ composites. The surface area of the $\mathrm{Mo}-\mathrm{CNT} / \mathrm{TiO}_{2}$ composites decreased due to the presence of molybdenum oxide and $\mathrm{TiO}_{2}$ particles on the surface of the CNTs. XRD revealed anatase in all samples, and confirmed the crystal structure of $\mathrm{MoO}_{2}$. The degradation of MB indicated that the addition of molybdenum enhanced the photocatalytic activity of the $\mathrm{Mo}-\mathrm{CNT} / \mathrm{TiO}_{2}$ composite. Moreover, the MoCT3 has good photocatalytic activity.

\section{Acknowledgement}

This work was supported by the Natural Science Project (KJ2010B047), Education Department of Anhui Province in China.

\section{References}

Asahi R, Morikawa T, Ohwaki T, Aoki K and Taga Y 2001 Science 293269

Bessekhouad Y, Robert D and Weber J V 2003 J. Photochem. Photobiol. A: Chem. 15747

Bhattacharyya A, Kawi S and Ray M B 2004 Catal. Today 98431

Carp O, Huisman C L and Reller A 2004 Prog. Solid State Chem. 3233

Chen X and Mao S S 2007 Chem. Rev. 1072891

Choi W, Termin A and Hoffmann M R 1994 J. Phys. Chem. 98 13669

Christensen P A, Curtis T P, Egerton T A, Kosa S A M and Tinlin J R 2003 Appl. Catal. B Environ. 41371

Dai H, Hafner J H, Rinzler A G, Colbert D T and Smaller R 1996 Nature $\mathbf{3 8 4} 147$

Devi L G, Kumar S G, Murthy B N and Kottam N 2009 Catal. Commun. 10794 
Di Paola A, Marci G, Palmisano L, Schiavello M, Uosaki K, Ikeda S and Ohtani B 2002 J. Phys. Chem. B106 637

Farag H, Whitehurst D D, Sakanishi K and Mochida I 1999 Catal. Today $\mathbf{5 0} 9$

Fu P F, Luan Y and Dai X G 2004 J. Mol. Catal. A: Chem. 22181

Hamal D B and Klabunde K J 2007 J. Colloid Interf. Sci. 311514

Jung K Y, Park S B and Jang H D 2004 Catal. Commun. 5491

Kozlova A E, Smirniotis P G and Vorontsov A V 2004 J. Photochem. Photobiol. A: Chem. 162503

Li Z R, Fua Y L, Bao J, Jiang M, Hu T D, Liu T and Xie Y N 2001 Appl. Catal. A Gen. 22021

Matsui H, Ishiko A, Karuppuchamy S and Yoshihara M 2009a J. Alloy Comp. 473 L33

Matsui H, Nagano S, Karuppucham S and Yoshihara M 2009b Curr. Appl. Phys. 9561
Neren Ökte A and Özge Y 2008 Appl. Catal. B: Environ. 8592

Oh W C and Chen M L 2008 Bull. Korean Chem. Soc. 29159

Oh W C, Jung A R and Ko W B 2007 J. Ind. Eng. Chem. 13 1208

Thompson T L and Yates J T 2006 Chem. Rev. 1064428

Yang S, Zhu W, Li X, Wang J and Zhou Y 2007 Catal. Commun. 8 2059

Yoneyama H and Torimoto T 2000 Catal. Today $\mathbf{5 8} 133$

Zhang Y, Zhang H B, Lin G D, Chen P, Zhu Y and Tsai K R 1999 Appl. Catal. A Gen. 187213

Zhang X W, Zhou M H and Lei L C 2005 Carbon 431700

Zhang F J, Chen M L and Oh W C 2008 Mater. Res. Soc. Korea 18 583

Zhang F J, Chen M L and Oh W C 2009 Korean Soc. Environ. Eng. 1432 